\title{
Sobre as formas de designar o universo da comunicação voltada para a promoção da democracia*
}

\section{On the ways of designating the universe of communication aimed at promoting democracy}

\author{
Marcelo Macedo ${ }^{1}$ \\ "Comunicar é comunicar-se em tôrno do significado significante" \\ Paulo Freire
}

\section{Resumo}

Desde o seu surgimento como campo específico da comunicação, o universo da comunicação voltada para a promoção da democracia, da cidadania e do desenvolvimento social vem sendo nomeado de diversas formas, tais como: alternativo, popular, contra-hegemônico, comunitário, livre, independente, midiativista. A partir da premissa de que essa multiplicidade de formas de designá-lo provoca dúvidas, confusões e conflitos no campo, o artigo promove o debate teórico em torno disto e oferece uma nova proposta de classificação. Tal proposta parte da ideia de que esse processo se refere sempre a um mesmo fenômeno, que varia conforme as suas condições de produção, quais sejam: os contextos político e econômico; o escopo geográfico dos conteúdos relacionados; e as tecnologias utilizadas. O texto traz à tona, também, o conceito de dialogia como inspiração teórico-metodológica para nomear o campo como um todo, apresentando seus fundamentos e mostrando que estes são próprios ao universo em questão.

Palavras-chave: comunicação dialógica; comunicação alternativa; comunicação popular; comunicação comunitária; midiativismo

\footnotetext{
*Revisor: Pedro Henrique Tenório

${ }^{1}$ Universidade do Estado do Rio de Janeiro
} 


\section{Introdução}

Desde o início do século passado, a antropologia de Durkheim \& Mauss (1990) nos mostra que o sistema semiótico do ser humano caracteriza-se por classificar as coisas. No nosso cotidiano, estamos sempre tentando mostrar para nós mesmos e para os outros que algumas coisas e pessoas existem e outras (crenças) não; que algumas dessas coisas e pessoas que existem são mais ou menos importantes que outras coisas que existem (valores); que essas coisas e pessoas devem estar sob determinadas regras (leis), e respeitar certos padrões de comportamentos (normas). Para tanto, estamos sempre classificando os universos com os quais lidamos. Esse ato envolve a designação, dar um nome (significante), que revela algo, o seu significado correspondente. O processo de troca de significados se dá por meio da comunicação. Como observa Dewey (apud WIRTH 1973, p. 231), a comunicação se refere, em primeiro plano, ao ato de "colocar em comum", compartilhar significados. A partir daí, podemos formular conceitos, definições que, seja no senso comum, seja no ambiente científico, nos ajudam a compreender e atuar no cotidiano.

Mas, e quando um determinado universo é marcado em sua constituição histórica por diversos significantes para designar uma mesma ideia, ou ideias muito próximas, de modo que não apenas se pode usar alternativamente um ou outro a cada fala, mas também não se sabe exatamente os limites entre um significado e outro? Pode-se imaginar que, nesses casos, há problemas de compreensão e comunicação.

Desde que embarquei no enorme navio da comunicação, há dez anos, sendo acomodado na escotilha a mim apresentada como "comunitária", percebo que a subárea é marcada pelo fenômeno semiótico identificado acima. Comunicação Comunitária? Comunicação Alternativa? Popular? Contra-hegemônica? Livre? Não é nada disso, agora sim temos o nome mais adequado: midiativismo! Enfim, o que está sendo expresso quando se utiliza cada um destes termos para designar esse universo? Há limites conceituais entre um e outro ou estamos falando sempre de uma mesma coisa? Como as inovações tecnológicas na comunicação afetam esse quadro conceitual?

A princípio, pode parecer que essas questões fazem parte de devaneios teóricos de meia dúzia de professores universitários dedicados ao tema. Mas, quem está pesquisando a área de forma participativa e vive os seus desafios cotidianos percebe que não, pois as indefinições e confusões conceituais têm afetado quem está na ponta, quem atua diretamente na área. Venho observando uma busca dentre estes pelo melhor termo, com a negação de uns 
e com classificações que também servem para separar o que é considerado legítimo daquilo que não é; ou seja, os significantes e seus significados correspondentes fazem parte do jogo político que classifica esse universo, que cria separações e uniões de acordo com visões distintas sobre ele. Portanto, estamos falando aqui de um problema de constituição do próprio campo, e não de uma questão exclusivamente "acadêmica". Afinal, como afirma Freire:

É então indispensável ao ato comunicativo, para que êste seja eficiente, o acôrdo entre os sujeitos, recìprocamente comunicantes. Isto é, a expressão verbal de um dos sujeitos tem que ser percebida dentro de um quadro significativo comum ao outro sujeito.

É então indispensável ao ato comunicativo, para que êste seja eficiente, o acôrdo entre os sujeitos, recìprocamente comunicantes. Isto é, a expressão verbal de um dos sujeitos tem que ser percebida dentro de um quadro significativo comum ao outro sujeito. (FREIRE, 1983, p. 46)

Este artigo propõe oferecer uma contribuição para esse problema. Minha proposta é fazer uma análise das principais designações utilizadas para nomear esse universo e tentar oferecer um quadro teórico que possa auxiliar na sua compreensão. Em termos metodológicos, a proposta está ancorada tanto em revisão bibliográfica sobre o tema, como no diálogo que temos mantido com os militantes que atuam nesse universo.

\section{Da multiplicidade de expressões à nova proposta de classificação}

Uma das principais referências conceituais para o universo aqui tratado é a Prof ${ }^{a}$. Cicilia Peruzzo e, mais especificamente, dois dos seus artigos que analisam e comparam as ideias de comunicação alternativa, popular e comunitária. Nesses trabalhos, a autora contextualiza cada uma dessas ideias e, embora não seja muito conclusiva a respeito, ora aponta para as "congruências" e as "distinções" entre os conceitos, dando a entender que se trata de três conceitos diferentes (2009, p.46); ora parece acreditar que, no fundo, estamos falando da mesma coisa:

A comunicação popular foi também denominada de alternativa, participativa, horizontal, comunitária e dialógica, dependendo do lugar social e do tipo de prática em questão. Porém, o sentido político é o mesmo, ou seja, o fato de tratar-se de uma forma de expressão de segmentos excluídos da população, mas em processo de mobilização visando atingir seus interesses e suprir necessidades de sobrevivência e 
de participação política. No entanto, desde o final do século passado passou-se a empregar mais sistematicamente, no Brasil, a expressão comunicação comunitária para designar este mesmo tipo de comunicação e também outras expressões similares. (PERUZZO, 2006 p. 2).

A autora mostra que o termo comunicação alternativa foi cunhado durante o período da ditadura militar, numa época em que se buscaram caminhos distintos às "verdades" que foram construídas por uma mídia cooptada e interessada em afagar as propostas do governo em um ambiente marcado pela censura e repressão em larga escala. Nesse contexto, o termo “alternativa" pareceu fazer bastante sentido e designou oposição ao estado de coisas vigente na época. Os principais veículos que materializaram essa ideia foram jornais e revistas, algumas de tom humorístico, que serviram para disfarçar seus conteúdos políticos, outras com este tom mais explícito, as quais foram criminalizadas, censuradas e circularam numa certa clandestinidade. Chagas (2013, p. 167), em sua tese sobre as bancas de jornais, aponta para o movimento de ataque às bancas que venderam jornais de esquerda no período da ditadura militar, e destaca que várias delas foram incendiadas como forma de intimidação.

O termo "comunicação popular" ganhou terreno no período da abertura democrática, num contexto de reativação dos movimentos sociais ancorados nas correntes progressistas da igreja católica e nos sindicatos. Ambos promoveram uma série de iniciativas de comunicação que procuraram dar voz a camadas sociais silenciadas pela ditadura militar. $\mathrm{O}$ adjetivo "popular", oriundo de "povo", expressou os anseios de inclusão social dessas camadas também por meio da produção e do acesso à informação. O final dessa década marcou o surgimento de experiências de jornais, rádios e tvs que ficaram marcadas na história dos movimentos populares. Destacaram-se nesse período as TVs de rua, que promoviam sessões para debater questões sociais relevantes, atraindo milhares de pessoas que se sentiram representadas politicamente tanto pela programação quanto pela possibilidade de participar dos debates que também foram projetados em praças públicas.

Como vimos na citação acima, Peruzzo localizou o surgimento do termo “comunicação comunitária" no início dos anos 1990. A autora não explicou ou comentou como o adjetivo "comunitária" foi alocado a esse universo, mas lanço aqui a hipótese de que essa ideia surge na esteira da onda que passou a chamar as favelas de comunidades. Seria relevante a realização de pesquisas para mostrar como ocorreu essa passagem semântica. ${ }^{1}$ Vale lembrar que esse período é marcado tanto pela proliferação das ONGs - que passaram a

\footnotetext{
${ }^{1}$ Nesse sentido, vale consultar a tese de Yamamoto (2013), sugerida por um dos revisores deste artigo.
} 
atuar e, muitas vezes, instalaram-se nas favelas -, quanto pela emergência das novas tecnologias da informação, embora estejamos ainda falando de uma época em que eram tímidos os desenvolvimentos da internet e o uso dos aparelhos celulares. De qualquer modo, após a popularização do videocassete na década de 1980, a emergência das primeiras câmeras digitais consolidou o barateamento do processo de produção de imagens, anunciando, pela primeira vez, possibilidades de quebra do paradigma do modelo broadcast. Vejamos como a autora define comunicação comunitária:

\begin{abstract}
Por tudo o que já foi analisado, a comunicação comunitária se caracteriza por processos de comunicação baseados em princípios públicos, tais como não ter fins lucrativos, propiciar a participação ativa da população, ter propriedade coletiva e difundir conteúdos com a finalidade de educação, cultura e ampliação da cidadania. Engloba os meios tecnológicos e outras modalidades de canais de expressão sob controle dos movimentos e organizações sociais sem fins lucrativos. Em última instância, realiza-se o direito à comunicação na perspectiva do acesso aos canais para se comunicar. Trata-se não apenas do direito do cidadão à informação, enquanto receptor - tão presente quando se fala em grande mídia -, mas do direito ao acesso aos meios de comunicação na condição de emissor e difusor de conteúdos. E a participação ativa do cidadão, como protagonista da gestão e da emissão de conteúdos, propicia a constituição de processos educomunicativos, contribuindo, dessa forma, para o desenvolvimento do exercício da cidadania. (PERUZO, 2006, p. 9-10).
\end{abstract}

Os meus grifos identificam aquilo que me parece mais relevante para definir o conceito segundo a autora. Paiva (2003), caminhou na mesma direção em sua tese de doutorado, que analisa em profundidade o debate teórico que envolve a distinção clássica entre comunidade e sociedade. A autora enfatiza o fazer e o sentido comunicacional orientado pela e para a comunidade - assim como o conteúdo político tratado - como as principais características dos veículos de comunicação que podem ser chamados de comunitários.

Mas, vejamos, o que há de efetivamente distinto entre o que Peruzzo chama de comunicação alternativa, popular e comunitária? Será que aqueles que exerciam atividades da chamada "comunicação alternativa" no período da ditadura são contra esses princípios identificados por Peruzzo para a "comunicação comunitária" e grifados por mim? O que a autora chamou de "comunicação popular" já não incorpora tudo isso? A autora dedica um dos subitens do seu artigo de 2006 ("Comunicação popular e comunitária: diversidade e convergência") para verificar as semelhanças e diferenças entre os dois conceitos. No 
entanto, no artigo e nesse item, só se percebem as semelhanças. Já nas considerações finais do artigo de 2009, a autora, embora os trate como sinônimos, segue percebendo diferenças entre os conceitos:

As práticas comunicacionais geraram conceitos que permitem tomar as expressões comunicação popular, alternativa e comunitária como sinônimos, quando se referem às lutas de segmentos subalternos por sua emancipação, mesmo havendo algumas características próprias em cada um dos processos (PERUZZO, 2009, p. 58).

A partir dos estudos realizados até aqui sobre o tema, minha resposta para esse conjunto de questões é: estamos falando sempre de uma mesma coisa, que se materializa e se desenvolve de formas diferenciadas de acordo com algumas variáveis. Entendo que há um mesmo objetivo em todos esses processos comunicativos, qual seja, o de produzir e difundir representações sociais mais fidedignas do que as apresentadas pelas mídias convencionais. Seja qual for o significante escolhido, estamos sempre falando de pessoas e grupos que se sentem mal representados pela mídia e, por isso, resolvem montar seus próprios veículos de informação. O que varia no processo de constituição desse universo são as condições sociais para o surgimento, o desenvolvimento, a multiplicação e a sustentabilidade dessas iniciativas. Nesse sentido, podemos apontar os seguintes aspectos (ou variáveis) para a análise:

\section{a) Contexto Político}

O contexto político torna-se uma variável relevante para o exercício da comunicação na medida em que o Estado não garante a vigência das leis que o fundamentam e que regulam as relações sociais. Presente na Declaração de Direitos Humanos e na Constituição do Brasil, a livre circulação de informações nunca foi garantida no país. Ao longo de nossa história, sempre tivemos que lutar para garantir o livre acesso à informação, assim como as possibilidades de produzi-la e difundi-la. Como se sabe, há períodos em que essas capacidades são, de forma violenta, restritas pelo aparato repressivo do Estado, sem que qualquer justificativa seja apresentada. Simplesmente, prende-se jornalistas, fecham-se jornais, rádios, impede-se o funcionamento de TVs, a circulação de periódicos etc. Assim, é evidente que o exercício da comunicação depende do valor que cada um dos governantes e suas equipes atribuem à democracia e à livre expressão. Ainda não houve um governo brasileiro, em qualquer esfera, que apoiasse de forma significativa a democratização das

comunicações. É como se houvesse uma relação necessária entre a governabilidade e o controle da produção de notícia. Parece ser preciso sempre uma mídia que promova a 
produção e reprodução de notícias que garantam a ordem pública e, sobretudo, a privada: o desfrute dos bens acumulados no sistema capitalista.

Portanto, nossa história é marcada por uma luta incessante pela garantia de liberdade da produção e circulação da informação. Não obstante, essa luta nunca aglutinou camadas expressivas da população, caracterizando-se como difusa, pouco efetiva, talvez pela dificuldade de visualização dos benefícios que podem decorrer dela. Há um certo consenso social sobre a concentração na mídia, sobre as manipulações que exerce e até sobre os prejuízos causados. No entanto, há enorme dificuldade de mobilização em torno dessa questão. Mas, independentemente disso, o fato é que a falta de apoio, a censura e a repressão inibem o exercício independente da mídia. Por exemplo, conforme já apontamos recentemente (MACEDO et al., 2017), o golpe de Estado recente no país inaugurou um novo período de dificuldades, com a prisão de midiativistas, o fechamento de jornais, a paralização de grupos que produziam informação para a internet e/ou a redução de suas atividades; o que se relaciona com a segunda variável, qual seja, as condições de sustentabilidade do veículo.

\section{b) Contexto Econômico (ou Condições de Sustentabilidade)}

Em relação a essa questão, vale ressaltar novamente a ausência de apoio aos grupos que fazem parte do universo tratado. Por isso, conforme já apontamos (MACEDO et al., 2013), a questão da sustentabilidade é nevrálgica. Inúmeras iniciativas surgem e logo são obrigadas a paralisar suas atividades em decorrência da falta de recursos. Portanto, no que se refere ao financiamento direto das atividades, essa é uma dificuldade que atravessa a história desse setor, sendo inerente a sua constituição.

Mas, independentemente dos apoios, a situação macroeconômica, ao condicionar a remuneração de militantes que atuam nesse tipo de comunicação, promovendo ou restringindo o seu tempo livre para tal atuação, tem reflexos importantes para as suas atividades. Em momentos de retração econômica, os comunicadores precisam restringir suas atividades de militância para se dedicar a seu próprio sustento e de suas famílias, o que resulta no recuo dos grupos. Em um cenário de políticas neoliberais, marcado por um Estado repressor e que se ausenta de suas prerrogativas sociais, como vivemos atualmente, as dimensões política e econômica caminham na mesma direção, dificultando a atuação dos grupos de mídia independentes.

c) Escopo geográfico dos temas abordados 
Chegamos então a uma terceira variável que, de forma distinta das outras, está sob o controle dos grupos que atuam no setor. Estamos falando da decisão de atuar de forma localizada ou difusa em relação aos conteúdos abordados, sendo essa uma decisão livre a ser tomada por cada grupo. Nesse sentido, poderíamos estabelecer, aqui, uma classificação dentro desse universo. Há os grupos que têm como objetivo criar representações sobre um território específico, em geral onde os próprios estão inseridos; e há grupos que não estão voltados para nenhum território específico, atuando de forma difusa em torno de questões que lhes interessam e, em geral, são de interesse para toda a sociedade.

Talvez o termo "comunicação comunitária" seja o mais adequado aos grupos que trabalham voltados para um território específico. Peruzzo (2006) e Paiva (2003) enfatizam que a comunicação comunitária é feita "pela comunidade" e "para a comunidade", o que restringiria o conceito aos grupos que atuam de forma territorial. ${ }^{2}$ No entanto, vale ressaltar que a literatura sobre o tema vem desprezando essa distinção aqui formulada. Não há distinção teórica entre o jornal de um sindicato profissional que trata de conjuntura política e um jornal editado por uma ONG num Complexo de Favelas, como se os dois estivessem submetidos às mesmas condições de existência, quando, na verdade, não estão. Enquanto o primeiro tem uma atuação muito mais independente, sendo talvez condicionado apenas pelos interesses específicos da categoria, que pouco ou nada restringem o escopo de suas publicações; o segundo provavelmente tem a seu dispor uma estrutura de produção mais frágil e presta contas às forças locais, que podem envolver religiosos, milicianos, comércio varejista de drogas e aparato repressivo do Estado.

A questão que permanece é como nomear esses dois tipos de comunicação que são claramente distintos entre si. Se o termo "comunicação comunitária" parece adequado para nomear aqueles veículos que atuam voltados para a produção de significados em torno de localidades específicas, como chamar aqueles que tratam de questões mais abrangentes, não restritas ou voltadas para um público específico? Parece-me que o termo "comunicação alternativa" expressa bem esse tipo de atuação. Este termo parece desgastado e esteve referido a um contexto específico conforme acabamos de apontar, àquele da ditadura militar brasileira. Não obstante, se estamos agora em um contexto com características bastante semelhantes (censura, repressão policial exacerbada, violência de estado, supressão de

\footnotetext{
${ }^{2}$ Esse foi o principal motivo que nos levou a rechaçar o significante "comunitário" no momento em que criamos o nosso Laboratório. Naquele momento, os grupos de midiativismo, cuja maioria atua de modo não territorial, estavam em evidência e, por isso, adotaram o termo que significava uma redução no universo ao qual nós gostaríamos de atuar.
} 
direitos etc.), inclusive com um vice-presidente militar, parece-me adequado e conveniente resgatá-lo. Portanto, em meus cursos e aulas, tenho usado essa tipificação. Tenho chamado de "comunicação comunitária" aquela voltada para um território específico; e "comunicação alternativa" aquela que, embora com os mesmos propósitos de oferecer outras representações em relação às mídias de massa, não está voltada para um território específico. Mas, essa última guarda algumas características bem distintas daquelas da década de 1970. E, em relação a essas distinções, as novas possibilidades tecnológicas aparecem como uma variávelchave.

\section{d) Tecnologias utilizadas}

Quando a ideia de "comunicação comunitária" foi forjada, estávamos no início do período marcado pela emergência da internet como nova tecnologia da informação. Se já havia autores internacionais apontando para as maravilhas da descoberta, tais como Jenking (2008) e Levy (2010), aqui no Brasil a descoberta era ainda incipiente, visto que pequena parcela da população tinha acesso à mesma. Não obstante, Peruzzo (2006) já apontava para o fato de que esse tipo de comunicação - lembrando que a tipificação estabelecida por ela obedece a critérios bem distintos daqueles que acabo de apresentar - ocorria em um novo contexto tecnológico, com a migração tecnológica para esse ambiente.

Como a bibliografia já mostrando cada vez mais exaustivamente, as novas tecnologias reduzem as distâncias, aumentam a velocidade do processo comunicacional, reduzem os custos de produção e, acima de tudo, aumentam as possibilidades de acesso à informação, interação e participação, favorecendo a dialogia. Estamos falando de um período anterior às manifestações de junho de 2013 e, ainda, anterior à chamada Primavera Árabe, tecida fundamentalmente pelas redes sociais. Além dessas duas experiências, podemos citar também o Occupy Wall Street (1999) - cujos autores localizam como a primeira experiência de vulto organizada a partir das redes sociais -, os piqueteiros na Argentina (2002) e os movimentos na Turquia (2013), como exemplos que marcam uma era de mobilizações na qual as novas tecnologias da informação vêm ocupando um papel central para as denúncias contra o Estado a difusão de informações e, a partir daí, a mobilização para ação política reivindicativa.

Nesse novo contexto, surge no Brasil o termo "midiativismo", com a variante "videoativismo", já que boa parte dessas ações de comunicação ocorrem com o uso da imagem em movimento como linguagem principal, combinada ao texto, nos mais diversos estilos. Como pode-se ver na citação abaixo, Ana Lúcia Nunes de Sousa, uma das principais 
estudiosas brasileiras do tema, em sua tese doutorado, prefere não entrar no debate a partir de definições, privilegiando a contextualização em cada situação. Mas, em certo momento, caracteriza o midiativismo como:

La ampliación de las posibilidades de ser tanto productor como audiencia de los médios informativos, abre espacio para que se pueda, como sugiere Fenton (2016, p. 10) "eludir la obsesión con la definición", sin perderse en el lodo descriptivo y enfocándose en el entorno social, político y económico, en el cual estos medios se insertan (cap. II). En este trabajo, se opta por partir de la noción de que estas prácticas mediáticas se insertan en la lucha contemporânea por lo común, eludiendo, por lo tanto, una parte de este debate conceptual para centrarse en algunos aspectos directamente relacionados a las prácticas analizadas.

En este sentido, se puede empezar localizando estas prácticas comunicativas entorno a Internet y a la idea del media activismo, conceptualización con la cual quedaron conocidos en Brasil quienes, a través de sus teléfonos móviles y cámaras portátiles, estaban reportando las protestas desde dentro del movimiento. Para Atton (2003, p. 15), "no debemos perder de vista el papel primordial de los activistas de los medios: el del activismo político". Así, un media activista "construye espacios comunicativos" (Kidd, 2007) y "encoraja lectores a participar activamente en cambios sociales. (Waltz, 2005, p. 3)”. (Sousa, 2016 p. 96).

Não estou de acordo com Sousa e Fenton quando sugerem que as novas tecnologias da informação introduzem possibilidades que nos permitem escapar do debate acerca de definições. Pelo contrário, essas novas tecnologias o que fazem é introduzir novos conceitos, tais como os de "mídia livre", "midiativismo" e "videoativismo", tornando o cenário mais complexo e confuso. A partir da sua caracterização sobre as práticas midiativistas, poderíamos dizer que o midiativista é aquele que, como participante de movimentos preocupados com transformações sociais, produz conteúdo para a internet.

Lembro-me bem que, ao longo do processo de entrevistas filmadas que realizamos, durante um intervalo de gravação, membros de um dos grupos que estavam produzindo audiovisual, mas que já atuavam há alguns anos também por meio de um jornal impresso, questionaram o uso do termo "midiativismo", alegando que este ativismo por meio da mídia, eles já faziam havia décadas e que, portanto, não parecia correto o uso do termo para dar sentido a uma prática que, na verdade, não seria nova. De fato, como vimos, o ativismo por meio da mídia remete ao século passado, não constituindo um fenômeno novo. O que aparece como novo é a utilização da internet para a circulação das representações formuladas pelos 
ativistas. Nesse sentido, nos parece que faz sentido utilizar o termo para designar a produção alternativa ou comunitária voltada para as redes sociais.

\section{A ideia de dialogia na classificação proposta}

Em resumo, minha proposta é que seja designada como comunicação comunitária a atuação de pessoas ou grupos que produzem representações sobre territórios específicos voltadas para a promoção da cidadania. Também defendo que seja chamada de comunicação alternativa aquela que, embora seja direcionada para esse mesmo objetivo, não tem como base um território específico, mas sim a pólis como um todo. Como midiativismo chamamos as práticas de comunicação comunitária ou alternativa que são produzidas para a veiculação na internet.

Poderíamos ter inventado novos significantes, sugerindo uma nova teoria da comunicação independente. Mas isso poderia gerar mais confusão. $\mathrm{O}$ que tentamos foi organizar, a partir dos significantes já utilizados e de uma certa lógica, a multiplicidade de termos para designar as variações de um mesmo fenômeno.

Percebam que acabei de chamar esse universo de "comunicação independente". O termo pretende diferenciar esse universo daquele a que este se opõe, o da comunicação voltada para o lucro. Não obstante, conforme já assinalamos antes (MACEDO et al., 2013), essa classificação carrega em si o problema de reduzir ou gerar confusão acerca de um dos seus aspectos mais importantes, qual seja, a luta pela sustentabilidade dos seus veículos. Embora não sejam voltados para o lucro, os veículos de comunicação comunitária e alternativa precisam obter recursos para se manterem ativos. Nesse sentido, são dependentes de uma série de condições sociais, econômicas e políticas, que vão desde a política macroeconômica do governo federal até as negociações com poderes locais, tais como as milícias e o comércio varejista de drogas. Por esse ângulo, até que ponto seria correto o termo “comunicação independente"? Parece-me que ele serve mais para condenar a dependência daqueles que flexibilizam suas linhas editoriais em troca de apoios financeiros do que propriamente para designar um universo marcado por diversas contradições e, como vimos, dependências.

Nesse ponto de vista, parece-me cada vez mais acertada a decisão tomada em 2012, a partir da influência de Paulo Freire - mais especificamente, do livro "Comunicação ou extensão" (FREIRE, 1983) -, de designar esse universo como o da comunicação dialógica. 
Entendo que a ideia de dialogia é a que melhor expressa os seus fundamentos. Que fundamentos são esses?

O que reúne todas as modalidades de atuação nesse universo que tentei classificar é o desejo de troca social que o permeia. Em oposição a um modelo comunicacional em que se identificam claramente emissores e receptores, a comunicação dialógica proposta por Freire supera essa distinção, colocando em pé de igualdade todos os envolvidos no processo comunicacional. Mesmo que os recursos de poder possam estar distribuídos de forma desigual, a busca pela equidade norteia o processo. Esteja voltado para um território específico ou não e, independentemente do meio utilizado, o caráter de cumplicidade entre os que participam do processo comunicacional é o fogo que o alimenta. Em vez de transmitir informações ou conhecimentos, busca-se a troca dos mesmos, a partir da percepção de que todos os envolvidos são capazes e responsáveis em também ofertá-los.

$\mathrm{Na}$ teoria sobre movimentos sociais, há quem advogue a importância dos chamados "agentes externos" para os processos de mobilização (GRYSZPAN, 1987). Há também quem, de forma oposta, advogue a necessidade da presença de moradores locais para caracterizar o processo (PERUZZO, 2006; PAIVA, 2003). Nossa experiência tem demostrado que, independentemente do local de residência do organizador do processo comunicacional, o fundamental é a cumplicidade entre os participantes envolvidos. Ao longo dos oito anos de pesquisa sobre o tema, já me deparei com comunicadores locais sem legitimidade e, ao inverso, com comunicadores que, embora morassem na zona sul da cidade do Rio de Janeiro, tinham legitimidade para atuar em favelas da zona norte. A mobilidade e as trajetórias sociais na cidade são diversas, contraditórias e complexas, importando mais a capacidade de diálogo e, a partir daí, a confiança que subjaz às relações de poder, as quais autorizam ou restringem os processos comunicacionais em espaços que, na maioria das vezes, não são regulados pelo estado de Direito, mas sim segundo lógicas próprias alheias ou, no mínimo, prevalentes a este.

Embutida no fundamento da troca-cumplicidade, há também na ideia de dialogia a valorização da democracia como proposta para a gestão da informação, seja no que se refere a uma divisão de poder mais equilibrada na gestão dos veículos em si; ou na valorização da participação de todos os interessados em desenvolver os processos de troca comunicacionais. Para exemplificar o que estamos querendo dizer aqui, comparemos os processos de produção e circulação da informação entre um jornal comercial e um jornal comunitário. No primeiro, 
os conteúdos são produzidos a partir de uma pauta definida por um diretor e implementada por alguns poucos editores a partir do trabalho pontual de repórteres no campo; e postos em circulação em bancas ou entregues em domicílios - ambos processos nos quais aquele que entrega o jornal não tem qualquer compromisso com o conteúdo do mesmo. No segundo, os conteúdos são definidos a partir de sugestões oferecidos por todos os envolvidos no processo: leitores, entregadores de jornal, repórteres, fotógrafos, editores e diretores; e a informação é posta em circulação por distribuidores que são conhecidos na localidade, têm relações pessoais com os leitores, em alguns casos leem o jornal para os analfabetos e, por tudo isso, participam do processo editorial levando sugestões de pauta, elogios e reclamações aos editores.

Outros fundamentos da dialogicidade são a valorização da história e, relacionada a esta, da diversidade social e cultural. $O$ apreço pela contribuição de todos os envolvidos decorre da percepção de que cada um tem uma história de vida, que cada sociedade tem uma história social, que são diversas entre si nesses dois âmbitos - individual e social -, mas que explicam as condições sociais que definem o contexto atual em que se situam os indivíduos, os fenômenos e as questões sociais tratadas nos processos comunicacionais. Em outras palavras, indivíduos e grupos sociais têm histórias próprias; e essa multiplicidade de histórias compõe as singularidades e a diversidade social, decorrendo daí a riqueza das vidas a serem narradas.

Os fundamentos aqui expostos podem ser resumidos nas seguintes palavras do autor:

Para nós, a "educação como prática da liberdade" é, sobretudo e antes de tudo, uma situação verdadeiramente gnosiológica. Aquela em que o ato cognoscente não termìna no objeto cognoscível, visto que se comunica a outros sujeitos, igualmente cognoscentes.

Na educação que seja verdadeiramente uma situação gnosiológica, não há, para o educador, um momento em que, sòzinho, em sua biblioteca ou em seu laboratório, conheceu, e outro em que, afastado dêste, simplesmente narra, disserta ou expõe o que conheceu. No momento mesmo em que pesquisa, em que se põe como um sujeito cognoscente frente ao objeto cognoscível, não está senão aparentemente só. Além do diálogo invisível e misterioso que estabelece com os homens que, antes dêle, exerceram o mesmo ato cognoscente, trava um diálogo também consigo mesmo. Põese diante de si mesmo. indaga, pergunta a si mesmo. E, quanto mais se pergunta, tanto 
mais sente que sua curiosidade em tôrno do objeto do conhecimento não se esgota. Que esta só se esgota e já nada encontra se êle fica isolado do mundo e dos homens. Daí a necessidade que tem de ampliar o diálogo - como uma fundamental estrutura do conhecimento - a outros sujeitos cognoscentes. Desta maneira, sua aula não é uma aula, no sentido tradicional, mas um encontro em que se busca o conhecimento, e não em que êste é transmitido. Precisamente porque não dicotomiza o seu quefazer em dois momentos distintos: um em que conhece, e outro em que fala sôbre seu "conhecimento" -, seu quefazer é permanente ato cognoscitivo.

$[\ldots]$

Os professôres que não fazem êste esfôrço, porque simplesmente memorizam suas lições, necessàriamente rejeitam a educação como uma situação gnosiológica, e assim não podem querer o diálogo comunicativo.

Para êles, a educação é a transferência de "conhecimentos"; consiste em estendê-los aos educandos passivos, com o que impedem nestes últimos e nêles o desenvolvimento da postura ativa e co-participante, característica de quem conhece.

Esta falsa concepção da educação, que se baseia no depósito de informes nos educandos, constitui, no fundo, um obstáculo à transformação; Por isto mesmo, é uma concepção anti-histórica da educação. (FREIRE, 1983, p. 53-55)

Percebam que os quatro fundamentos da dialogicidade apresentados independem de qualquer questão tecnológica. No entanto, há alguns anos, houve quem sugerisse que a internet significaria um salto em direção à democracia, dados o aumento das possibilidades de produção, veiculação e circulação de notícias pelas redes sociais. A liberação do polo de emissão e a possibilidade de trocas em ferramentas, como blogs e o Facebook, segundo estes otimistas, promoveriam a atualização da esfera pública em novas bases, agora por meios digitais (LEVY, 2010; JENKINGS, 2008).

De fato, as redes sociais ampliaram as possibilidades de produção de informação para quem tem acesso a elas. Nesse ponto de vista, alguns processos de mobilização social para reivindicação de direitos e/ou em oposição às violências de Estado ocorreram a partir de tais possibilidades. Já citamos na seção anterior alguns exemplos disso. As redes sociais se mostraram uma tecnologia fundamental em quase todos os processos de mobilização social do início deste século e, como resultado, tivemos o abalo do status quo em todos esses países. $\mathrm{Na}$ esteira desses processos, foi abalada também a grande mídia, na medida em que se tornou evidente o modo parcial como apresentava os fatos, que passaram a ser vistos por um outro 
ponto de vista, aquele do movimento midiativista que, imerso nas mobilizações, trazia à tona outras narrativas.

No entanto, tão logo essas novas ferramentas apresentaram seus primeiros resultados de democratização, governos e provedores de internet trataram de restringir o acesso ilimitado às informações nas redes sociais. A criação de algoritmos que limitam o alcance das publicações significou um freio na circulação de informações nas redes sociais que, a princípio, era livre. Tais algoritmos promoveram a criação das chamadas "bolhas" da internet, nas quais nos vemos presos ao atingir sempre as mesmas pessoas com o mesmo tipo de informação. Ao invés de promover o diálogo com o diferente, passamos a alimentar as polaridades, na medida em que bombardeamos de informação ideologicamente semelhante os mesmos pares, enquanto outras correntes fazem o mesmo em suas respectivas "bolhas". Somam-se a esse fenômeno as dificuldades de controle da emissão em redes como o WhatsApp, onde se pode automatizar não somente o envio de mensagens falsas para listas de milhares de pessoas, mas ainda o recolhimento e a venda de informações pessoais contidas na rede para fins comerciais e políticos. Recentemente, tivemos processos eleitorais fraudados dessa forma nos EUA, no Paraguai e no Brasil, com graves danos às democracias desses países.

Portanto, aquele otimismo inicial parece ter ficado para trás. Hoje, ao contrário, boa parte dos autores vê a internet como uma ferramenta que promove o aprofundamento do controle social no sistema capitalista. São necessárias mais pesquisas que analisem a capacidade de promover a dialogia nas redes sociais, mas alguns resultados preliminares, como os de Nunes (2016), que analisou a participação social nas redes a partir de postagens de grupos videoativistas, demonstraram a sua timidez, no sentido da promoção de uma esfera pública por meios digitais. Ao contrário, o que aparece de forma cada vez mais nítida é a separação entre ideologias de esquerda e direita, com a proliferação de discursos de ódio de parte a parte e a geração de "apartheids sociais".

\section{Considerações Finais}

Este texto discutiu as principais designações para o universo das representações alternativas à mídia convencional. Vimos que há uma enorme diversidade de termos para denominar esse universo - alternativo, popular, comunitário, livre, contra-hegemônico, 
independente, crítico, midiativista -, e que tanto os cientistas sociais quanto os militantes da área utilizam esses termos de forma às vezes aleatória, eventualmente para ressaltar alguma característica que se deseja expressar, mas, em geral, com pouco rigor metodológico e científico. Embora a utilização dos termos pelos militantes seja pouco rigorosa, vale ressaltar que esta não é desprovida de importância para eles, já que os termos servem também como ferramentas nas disputas dentro do campo. Por exemplo, denominar-se um grupo como “independente", em determinada situação, pode significar uma acusação a um grupo rival considerado "dependente". Portanto, não estamos tratando de um problema meramente teórico ou acadêmico, mas sim de algo que afeta o cotidiano da prática no campo.

Nesse debate, mostramos que, de modo geral, estes diversos significantes expressam um mesmo sentido, qual seja, o desejo de oferecer representações sociais diferentes daquelas oferecidas pelas mídias convencionais, cuja preocupação primordial é a busca do lucro econômico. A multiplicidade de designações para esse universo deriva do acúmulo de termos que foram sendo propostos e aceitos (ou institucionalizados) em diferentes períodos históricos. Em outras palavras, ao longo da trajetória da área, no fundo, estivemos sempre falando de uma mesma coisa, mas utilizando diferentes significantes de acordo com o que estava "na moda" em cada período. Vimos que o que varia ao longo do tempo são as condições para tal prática social. Nesse sentido, identificamos como variáveis: o contexto econômico; o contexto político; o escopo geográfico de atuação; e as tecnologias utilizadas.

Essa multiplicidade de termos não inviabiliza a tentativa de organizar o debate conceitual. Pelo contrário, entendemos que esta é uma tarefa importante para diferenciar práticas que se mostram efetivamente distintas dentro desse universo. Nesse sentido, propusemos uma classificação própria - a partir da variável "escopo geográfico", classificamos o tipo de comunicação voltado para o desenvolvimento de um território específico como "comunitário", enquanto aquele que não está voltado para um território específico como "alternativo". E, baseado em critério tecnológico, decidimos chamar de "midiativismo" a produção de representações voltadas para as redes sociais da internet.

Procuramos mostrar que o termo que melhor expressa esse universo é "comunicação dialógica”. Inspirados na proposta metodológica de Freire (1983), identificamos que este termo carrega em si os fundamentos que definem da forma mais exata o que há de comum ao trabalho desenvolvido pelos indivíduos e grupos. Vimos como os princípios da cumplicidade (troca/reciprocidade); da democracia; e da valorização da história e da diversidade cultural, 
ao mesmo tempo, oferecem sustentação ideológica e norteiam as práticas no campo. A escolha do termo não se deve somente a sua importância histórica, abrangência e significado metodológico, mas também ao fato de este significado estar mais livre de juízos de valor e dos desgastes inerentes àqueles que não estão.

Por fim, procuramos mostrar que, embora as tecnologias influenciem nas práticas da comunicação dialógica, compondo uma variável importante de análise, são incapazes de determiná-la. Mostramos ainda que se por um lado, as tecnologias digitais promoveram a democratização da produção, por outro, estão sendo estabelecidos limites estreitos para a distribuição e circulação das informações, está diminuindo o controle sobre a qualidade dos conteúdos produzidos e aumentando a polarização em detrimento do debate cordial; também está sendo violada a privacidade dos cidadãos por meio da utilização dos seus dados com fins econômicos e políticos. Todos esses fatores, em conjunto, ao invés de promoverem a dialogicidade, como pregaram os amantes do mundo digital, estão promovendo o controle social e reduzindo as perspectivas de expansão da democracia no planeta. 


\section{Referências Bibliográficas}

CHAGAS, Viktor. EXTRA! EXTRA! Os jornaleiros e as bancas de jornais como espaço de disputas pelo controle da distribuição da imprensa e da economia política dos meios. 2013. Tese (Doutorado em História, Política e Bens Culturais. Programa de Pós-Graduação em História, Política e Bens Culturais [PPHPBC] do Centro de Pesquisa e Documentação de História Contemporânea do Brasil [CPDOC] da Fundação Getúlio Vargas [FGV]). Rio de Janeiro, 2013.

DURKHEIM, Émile; MAUSS, Marcel.. Algumas formas primitivas de classificação. In: MAUSS, Marcel. Ensaios de sociologia. 2. ed. São Paulo: Perspectiva, 1999 [1903]. p. 399455 .

FREIRE, Paulo. Extensão ou comunicação? Rio de Janeiro: Paz e Terra, 1983.

GRYNSZPAN, Mário. Mobilização Camponesa e Competição Política no Estado do Rio de Janeiro (1950-1964). 1987. 376 f. Dissertação (Mestrado em Antropologia Social). Museu Nacional/UFRJ. Rio de Janeiro, 1987.

JENKINS, Henry. Cultura da Convergência. São Paulo: Editora Aleph, 2008.

LÉVY, Pierre. Cibercultura. São Paulo: Editora 34, 2010.

MACEDO, Marcelo Ernandez; PIRES, Flávio da Rocha; CARDOSO, Alessandra. A formação de grupos de midiativismo no Rio de Janeiro. Revista Alceu, v. 18, n. 35, p. 94113, jul./dez. 2017.

MACEDO, Marcelo Ernandez; SEIDEL, A.; FERREIRA, M.. O Jornal O Cidadão e os desafios para a sustentabilidade de veículos de comunicação comunitária. Comunicação \& Política, v. 31, p. 134-151, 2013.

NUNES, Ana Lúcia. De la calle a la red - videoactivismo em el contexto de las protestas em contra del mudial del fútbol en Rio de Janeiro 2014. 2017. 315f. Tese (Doutorado). Universidade Federal do Rio de Janeiro / Universidad Atonoma de Barcelona. Barcelona, 2017.

PAIVA, Raquel. O espírito comum - comunidade, mídia e globalismo. Rio de Janeiro: Mauad, 2003 
PERUZZO, Cicília Revisitando os Conceitos de Comunicação Popular, Alternativa e Comunitária. Trabalho apresentado na Intercom - Sociedade Brasileira de Estudos Interdisciplinares da Comunicação -, XXIX Congresso Brasileiro de Ciências da Comunicação - UnB. 6 a 9 de setembro de 2006. p. 1-17. Disponível em: <http://www.portcom.intercom.org.br/pdfs/116338396152295824641433175392174965949.pdf>.

Conceitos de comunicação popular, alternativa e comunitária revisitados e as reelaborações no setor. Revista ECO-Pós, v. 12, n. 2. Rio de Janeiro: Programa de PósGraduação em Comunicação/UFRJ, maio/agosto 2009, p. 46-61. Disponível em:

<https://revistas.ufrj.br/index.php/eco_pos/article/viewFile/947/887>.

WIRTH, L. Delineamentos e problemas da comunidade. In: FERNANDES, F. (Org.). Comunidade e sociedade: leituras sobre problemas conceituais, metodológicos e de aplicação. São Paulo: Nacional/Edusp, 1973.

YAMAMOTO, Eduardo Yuji. A questão da comunidade na era da midiatização: crítica e ontologia. 2103. 294 f. Tese (Doutorado apresentada ao Programa de Pós-Graduação em Comunicação da UFRJ). ECO/UFRJ. Rio de Janeiro, 2013. 